\title{
Nanofiber-enrich activated carbon coin derived from tofu dregs as electrode materials for supercapacitor
}

\author{
Erman Taer ${ }^{\mathrm{a},},{ }^{*}$, Apriwandi ${ }^{\mathrm{a}}$, Fainida Hasanah ${ }^{\mathrm{a}}$, Rika Taslim ${ }^{\mathrm{b}}$ \\ ${ }^{a}$ Department of Physics, Faculty of Mathematic and Natural Sciences, University of Riau, Riau, 28293, Indonesia \\ ${ }^{b}$ Department of Industrial Engineering, State Islamic University of Sultan Syarif Kasim, Riau, 28293, Indonesia
}

Article history:

Received: 25 May 2021 / Received in revised form: 1 June 2021 / Accepted: 3 June 2021

\begin{abstract}
In this study, the activated carbon with enriched nanofiber obtained from free-binder materials. It was conducted tofu dregs carbon nanofiber as electrode material for supercapacitor without the addition of $\mathrm{pVdF} / \mathrm{PTFE}$. The chemical impregnation of $\mathrm{NaOH}_{2} \mathrm{ZnCl}_{2}$ and $\mathrm{H}_{3} \mathrm{PO}_{4}$ at hightemperature pyrolysis in an $\mathrm{N}_{2}-\mathrm{CO}_{2}$ environment converted the tofu dregs into carbon coin. Subsequently, the physical properties including, microcrystalline, morphology, element analysis, and electrochemical properties of specific capacitance were investigated. The morphological structure of activated carbon showed high nanofiber density and was decorated by sponge-like pores. In addition, the nanofiber contains oxygen content of $12.70 \%$ which can act as self-doping due to the pseudo-capacitance properties. Furthermore, the two-electrode system obtained a specific capacitance of $163 \mathrm{~F} \mathrm{~g} \mathrm{~g}^{-1}$ in $1 \mathrm{M} \mathrm{H}_{2} \mathrm{SO}_{4}$ electrolyte. The results showed that tofu dregs-based activated carbon coins are sustainable and efficient to obtain high-dense nanofiber structure as electrode materials for energy storage applications.
\end{abstract}

Keywords: Nanofiber; carbon coins; tofu dregs; electrode material; supercapacitor

\section{Introduction}

Supercapacitors are considered as one of the relatively ideal energy storage that can be applied to a variety of digital equipment, electric vehicle, cranes, and laser systems $[1,2]$. This is due to its relatively easy-to-understand principles, short charge-discharge process, almost unlimited life cycle, and high durability [3]. For almost two decades, improving performance has been inextricably linked with advances in nanotechnology, especially in the fields of materials science and nanomaterials. These fields provide a variety of electrodebased materials including carbon [4], graphene [5], and synthetic polymers [6]. Furthermore, they are provided in various nanometer-scale sizes including nanofibers, nanotubes, nanowire, nanosphere, and nanosheet. Among these various materials, carbon nanofiber has shown remarkable performance in improving energy storage for supercapacitors and other devices such as lithium batteries, fuel cells, water purification applications, and medical applications [7,8]. However, the synthesis is complicated because of the difficulty to obtain a high-density fiber structure.

Biomass and bio-waste are the most popular carbon-based materials recently used in supercapacitor electrode applications. This is due to their abundant availability, easy production process, cost-effectiveness, and high surface area.

* Corresponding author.

Email: erman.taer@lecturer.unri.ac.id

https://doi.org/10.21924/cst.6.1.2021.407
Furthermore, they allow the presence of nanoscale morphological structures including nanofibers, nanotubes, and nanosheets $[9,10]$. Biomass can easily be converted to activated carbon through heat treatment in a certain gaseous environment $\left(\mathrm{Ar} / \mathrm{N}_{2} / \mathrm{CO}_{2} / \mathrm{H}_{2} \mathrm{O}\right)$, chemical impregnation $(\mathrm{KOH}$, $\left.\mathrm{NaOH}, \mathrm{ZnCl}_{2}, \mathrm{H}_{3} \mathrm{PO}_{4}\right)$, or a combination of both [11,12]. The main constituent components include lignocellulose consisting of hemicellulose, cellulose, and lignin, which allow the production of activated carbon with tubular [13], rod-like [14], strobili-fiber [15], microsphere [16], nanotube [17], and nanosheet [18] morphologies. Meanwhile, chemical impregnation with high-temperature pyrolysis in a certain gas environment can optimize the fibrils and cellulose in the biowaste components to produce high-density nanofibers [19]. This is due to its hemicellulose, cellulose, and lignin composition, which are connected by b-1-4-linkages and hydrogen bonds [20]. The bond can be removed in the component framework through a pyrolysis process to produce carbon nanofibers. For example, activated carbon nanofiberbased on acacia leaves waste has been successfully obtained through a chemical $\mathrm{KOH}$ impregnation and physical activation, with a capacity of $113 \mathrm{~F} \mathrm{~g}^{-1}$ [21]. In addition, several result was found in other studies [22]. However, biowaste and biomass do not always produce a nanofiber structure on activated carbon as raw materials. Therefore, it is necessary to select the types that contain an effective percentage of lignocellulose content.

One of the bio-wastes that have the potential to be used as a carbon nanofiber-based material is tofu dregs. In the food 
industry, tofu has an important role because of its high protein content [23], and the development of increasingly sophisticated industrial technology has led to large quantities of production. This is also followed by the number of dregs, which are commonly called tofu dregs. The residual protein contained can offer a nitrogen component and high lignocellulose content for carbon materials [24]. Furthermore, the chemical impregnation process and the right pyrolysis temperature can produce activated carbon with a nanofiber morphological structure.

This study synthesized activated carbon nanofiber through facile with chemical impregnation at $\mathrm{N}_{2}-\mathrm{CO}_{2}$ pyrolysis. This method is cost-effective, and without polymers from tofu biowastefor supercapacitor electrodes. Furthermore, activated carbon was synthesized using chemical impregnation of $\mathrm{NaOH}, \mathrm{ZnCl}_{2}$, and $\mathrm{H}_{3} \mathrm{PO}_{4}$ followed by pyrolysis at a high temperature of $850{ }^{\circ} \mathrm{C}$ in an $\mathrm{N}_{2}-\mathrm{CO}_{2}$ gas environment. To maintain the real conductivity of the basic material, the activated carbon electrode was prepared in the form of a coin without the addition of PVDF/PTFE. The morphological structure confirms the presence of high nanofiber with carbon and oxygen contents of $87.88 \%$ and $12.70 \%$ respectively. Moreover, the electrochemical feature has a high specific capacitance of $163 \mathrm{~F} \mathrm{~g} \mathrm{~g}^{-1}$ in $1 \mathrm{M} \mathrm{H}_{2} \mathrm{SO}_{4}$ electrolyte. These results suggest that tofu dregs-based activated carbon coins are sustainable and efficient to obtain high-density nanofiber structure by being chemically impregnated at hightemperature pyrolysis as electrode materials for supercapacitors.

\section{Materials and Methods}

\subsection{Synthesis of activated carbon coins nanofiber}

The basic material of tofu dregs is obtained from the production house of medium-sized businesses in Pekanbaru city. Meanwhile, chemical substances including $\mathrm{ZnCl}_{2}$, $\mathrm{NaOH}$, and $\mathrm{H}_{3} \mathrm{PO}_{4}$ with purity of $\pm 98 \%$ were obtained from Merck KGaA, 64271 Darmstadt. The tofu dregs were washed, cleaned for further pre-carbonization, and chemically activated in $0.5 \mathrm{~m} \mathrm{~L}^{-1}$ using three different reagents as $\mathrm{ZnCl}_{2}$, $\mathrm{NaOH}$, and $\mathrm{H}_{3} \mathrm{PO}_{4}$. For comparison, a sample without chemical impregnation was provided as a sample powder in a heterogeneous form $<60 \mu \mathrm{m}$. Furthermore, it was converted into solid coin form without the addition of any adhesive component such as polyvinyl or others. The pyrolysis process was conducted in a furnace tube using $\mathrm{N}_{2}$ and $\mathrm{CO}_{2}$ gas atmosphere at a maximum high temperature of $850{ }^{\circ} \mathrm{C}$, and the coin samples were then neutralized in DI water $(\mathrm{pH}=7)$.

\subsection{Characterizations}

Carbon nanofiber coins were characterized by several methods including density changes, crystallinity, surface morphology, chemical elements confirmed, and capacitive properties of supercapacitor cells. The change in density $(\rho)$ was evaluated by measuring the mass, diameter, and height of the carbon coins, and was calculated twice, before and after the pyrolysis process using standard equations [25].

$$
\rho=m / V
$$

Furthermore, the crystallinity properties were confirmed by $\mathrm{X}$-ray diffraction with $\mathrm{Cu} \mathrm{K} \alpha$ radiation in $2 \theta$ angel of $15^{\circ}-65^{\circ}$ at $\mathrm{V}=40.0 \mathrm{kV}$ and $\mathrm{I}=30 \mathrm{~mA}$ using the Shimadzu-7000L instrument. The surface morphology and chemical elements in the sample were reviewed through the SEM-EDS method using the JEOL-JSM-360LA instrument. Moreover, electrochemical properties such as specific capacitance, specific energy, and power were evaluated by using cyclic voltammetry (CV) and galvanostatic charge-discharge (GCD) techniques. The supercapacitor cells were prepared in the form of sandwich layers consisting of two carbon nanofiber coins-based electrodes, an organic separator, and a stainless steel current collector. Meanwhile, the CV method was applied to a 0-1 constant voltage window with various scan rates of $1,2,5$ and $10 \mathrm{mV} \mathrm{s}^{-1}$ and the specific capacitance $\left(\mathrm{C}_{\mathrm{sp}}\right)$ was evaluated using the following equation (2) [26]:

$$
C_{s p}=2 I / s \cdot m
$$

Furthermore, the GCD technique was evaluated at a constant current density of $1 \mathrm{~A} \mathrm{~g} \mathrm{~g}^{-1}$ with the capacitive behavior $\left(\mathrm{C}_{\mathrm{sp}}\right)$ determined according to the following equation (2) [26,27]:

$$
C_{s p}=I \cdot \Delta t / m \cdot \Delta v
$$

Specific energy $\left(\mathrm{E}_{\mathrm{sp}}\right)$ and specific power $\left(\mathrm{P}_{\mathrm{sp}}\right)$ were evaluated using standard formulas $(3,4)[16,28]$ :

$$
\begin{gathered}
E_{s p}=C_{s p} \cdot V^{2} / 7.2 \\
P_{s p}=3600 \cdot E_{s p} / \Delta t
\end{gathered}
$$

\section{Results and Discussion}

\subsection{Density analysis of carbon coin nanofiber}

The chemically activated carbon samples include $\mathrm{NaOH}$, $\mathrm{ZnCl}_{2}$, and $\mathrm{H}_{3} \mathrm{PO}_{4}$ in the form of solid coins without adhesive materials at high-temperature pyrolysis. They require initial confirmation to evaluate the success of converting biomass into porous activated carbon coins with a nanofiber structure. This initial confirmation is conducted by evaluating the dimensions of mass, thickness, and diameter in the pyrolysis process which is accumulated in the density changes based on equation (1). Figure 1 shows the changes in density before and after the pyrolysis process with $\mathrm{N}_{2}-\mathrm{CO}_{2}$ stages. All samples showed a reduction in density after pyrolysis, and this is natural because high temperature can decompose and evaporate volatile elements and water content. Furthermore, it may also break down hemicellulose, cellulose, and lignin compounds in the form of $\mathrm{CO}, \mathrm{CO}_{2}$, and $\mathrm{NH}_{4}$ gases [29]. The final process creates empty spaces in the coin sample and allows the presence of multiple pore structures to reduce their density. Furthermore, $\mathrm{N}_{2}-\mathrm{CO}_{2}$ integrated pyrolysis allows more breakdown of the hemicellulose and lignin [30] attached to the cellulose, and it indicates the presence of a nanofiber structure in the sample [15]. These physical structures favor porous activated carbon to improve the electrochemical properties of the supercapacitor. In addition, this analysis was further confirmed by SEM micrographs and CV/GCD profiles. Before pyrolysis, each sample of TD-Inactivation, TD-NaOH, TD-ZNCl 2 , and $\mathrm{TD}-\mathrm{H}_{3} \mathrm{PO}_{4}$ had a density of $0.9328, \quad 0.9510,1.0144,0.9472 \mathrm{~g} \mathrm{~cm}^{-3}$, respectively. 
Meanwhile, after pyrolysis with $\mathrm{N}_{2}-\mathrm{CO}_{2}$ level at a high temperature of $850{ }^{\circ} \mathrm{C}$, the density drastically decreased reaching $59.72 \%, 47.57 \%, 24.63 \%$, and $11.99 \%$ in $\mathrm{TD}-\mathrm{ZnCl}_{2}$, TD-NaOH, TD- $\mathrm{H}_{3} \mathrm{PO}_{4}$, and TD-Inactivation respectively. The $\mathrm{ZnCl}_{2}$ Impregnation shows the greatest density reduction compared to $\mathrm{NaOH}$ and $\mathrm{H}_{3} \mathrm{PO}_{4}$. This is because $\mathrm{ZnCl}_{2}$ is a dehydrating agent in biomass-based that reacts faster at 600 ${ }^{\circ} \mathrm{C}$ pyrolysis temperature and oxidizes as well as evaporates impurities. Furthermore, $\mathrm{ZnO}$ as an impregnation co-product allows the etching of carbon to form a pore framework on the surface of the sample [31]. The basic reaction between carbon and $\mathrm{ZnCl}_{2}$ was shown in equation $(6,7)$ [32].

$$
\begin{aligned}
& \mathrm{ZnCl}_{2}+1 / 2 \mathrm{O}_{2} \rightarrow \mathrm{ZnOCl}+1 / 2 \mathrm{Cl}_{2} \\
& 2 \mathrm{ZnO}+\mathrm{C} \rightarrow 2 \mathrm{Zn}+\mathrm{CO}_{2} \uparrow
\end{aligned}
$$

These results showed that the chemical impregnation on $\mathrm{N}_{2}-\mathrm{CO}_{2}$ integrated pyrolysis was successful in converting tofu dregs to porous activated carbon coins.

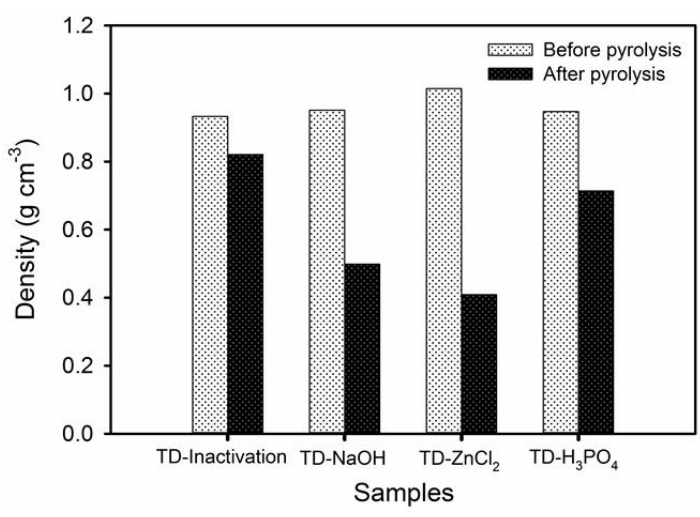

Fig. 1. Density of carbon coin nanofiber

\subsection{Microstructure features}

The microstructural features of activated carbon nanofiber were examined using the XRD technique as shown in figure 2. Generally, the XRD pattern show the presence of strong peaks in the reflection planes [002] and [100]. Furthermore, it correlates with $2 \theta$ angles approximately $22-25^{\circ}$ and $43-45^{\circ}$ and this showed that all samples impregnated with the activating agent have an amorphous carbon structure $[33,34]$. The reflection plane [002] at $22-25^{\circ}$ indicates a hexagonal configuration of porous carbon and the existence of a small amount of graphite microcrystalline structure [35]. In addition, reflections [100] about $43-44^{\circ}$ confirmed the presence of multiple pore structures due to interlayer condensation processes by $\mathrm{sp}^{2}$-hybridized carbons (JCPDS No. 41-1487). However, TD- $\mathrm{ZnCl}_{2}$ has the lowest $2 \theta$ angles for the reflection plane [002] of $22.571^{\circ}$ and the smallest for [100] of $43.848^{\circ}$ compared to other samples.

\begin{tabular}{|c|c|c|c|c|c|c|}
\hline Samples & $2 \theta_{002}\left({ }^{\circ}\right)$ & $2 \theta_{100}\left({ }^{\circ}\right)$ & $\mathrm{d}_{002}(\AA)$ & $\mathrm{d}_{100}(\AA)$ & $\mathrm{L}_{\mathrm{c}}(\AA)$ & $\mathrm{L}_{\mathrm{a}}(\AA)$ \\
\hline TD-NaOH & 25.875 & 43.895 & 3.440 & 2.060 & 9.159 & 28.928 \\
\hline $\mathrm{TD}-\mathrm{ZnCl}_{2}$ & 22.571 & 43.848 & 3.936 & 2.058 & 8.153 & 23.755 \\
\hline TD- $\mathrm{H}_{3} \mathrm{PO}_{4}$ & 23.920 & 44.174 & 3.717 & 2.048 & 13.571 & 11.560 \\
\hline
\end{tabular}

Table 1. Interlayer spacing, stack height, and stack width of carbon coin
This is because the $\mathrm{ZnCl}_{2}$ impregnation produces a relatively more random combination of micropores and mesoporous [36] and it corresponds to the data shown in the previous density reduction. In addition, a small number of sharp peaks were found at a $2 \theta$ angle of $37.47^{\circ}$ which confirmed the presence of crystalline compounds from $\mathrm{CaCO}_{3}$ [14]. The analysis was also confirmed by the EDS data shown in the subsection below, and the appearance of $\mathrm{CaCO}_{3}$ compounds was speculated from the basic constituent elements of tofu dregs which are not completely decomposed by $\mathrm{N}_{2}-\mathrm{CO}_{2}$ pyrolysis. Table 1 shows the average interlayer spacing of $\mathrm{d}_{002}$ and $\mathrm{d}_{100}$ of TD-NaOH, TD- $\mathrm{ZnCl}_{2}$, and TD$\mathrm{H}_{3} \mathrm{PO}_{4}$, which was evaluated by using Bragg's Law. The $\mathrm{d}_{002}$ exhibited value in the range of $3.440-3.936 \AA$ while $\mathrm{d}_{100}$ presented the value of 2.060-2.058 $\AA$ and were increased by $15 \%$ compared to normal graphite structures. These values are also similar to others reported by using different raw materials such as pineapple crown [37] and an empty fruit bunch of palm oil [38]. Table 1 also shows the microcrystalline dimension such as stack height $\left(\mathrm{L}_{\mathrm{c}}\right)$, and width $\left(\mathrm{L}_{\mathrm{a}}\right)$ was evaluated by the Debye-Scherrer equation [39]. TD- $\mathrm{ZnCl}_{2}$ sample has the lowest $\mathrm{L}_{\mathrm{c}}$ value than TD$\mathrm{NaOH}$, and $\mathrm{TD}-\mathrm{H}_{3} \mathrm{PO}_{4}$ samples, while the ratio between Lc and $\mathrm{L}_{\mathrm{a}}$ was decreased. Furthermore, each microcrystalline dimension can be used as a reference to determine the specific surface area of the sample. The relationship between stack height $\mathrm{L}_{\mathrm{c}}$ and specific surface area is shown in the empirical formula $\mathrm{SSA}_{\mathrm{xrd}}=2 / \rho_{\mathrm{xrd}} \mathrm{L}_{\mathrm{c}}[40,41]$. Based on this, the highest surface area discovered in the $\mathrm{TD}-\mathrm{ZnCl}_{2}$ sample was predicted with TD-NaOH and TD- $\mathrm{H}_{3} \mathrm{PO}_{4}$. This speculation is consistent with the density reduction analysis discussed above and it greatly improved the capacitive properties of the supercapacitor electrodes.

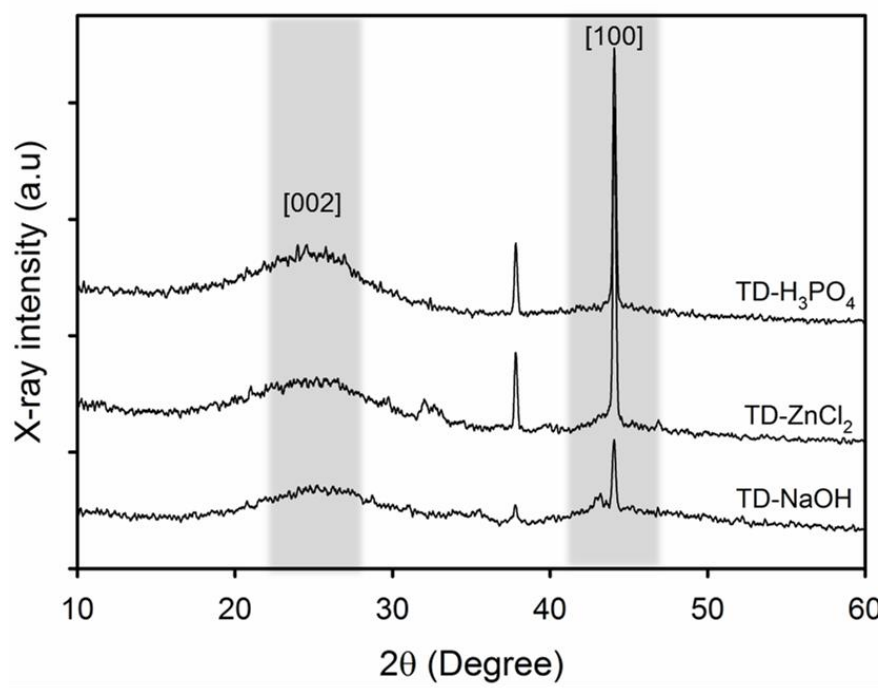

Fig. 2. XRD pattern of carbon coin nanofiber

\subsection{Morphological analysis}

Figure 3 illustrates that the morphological structure of the activated carbon coins nanofiber was evaluated using SEM techniques. The micrographs in figure 3 perform the surface morphology of TD-NaOH, TD- $\mathrm{ZnCl}_{2}$, and $\mathrm{TD}-\mathrm{H}_{3} \mathrm{PO}_{4}$ samples. Furthermore, they were pyrolyzed in an $\mathrm{N}_{2}-\mathrm{CO}_{2}$ 
gasses environment of high temperature $850{ }^{\circ} \mathrm{C}$. The TD$\mathrm{NaOH}$ sample displayed dense nanofiber structures with diameters ranging from $54-285 \mathrm{~nm}$. NaOH impregnation and high-temperature pyrolysis optimized the fibril and cellulose in the lignocellulosic component of biomass to produce highdensity nanofibers. This is due to the composition of tofu dregs which contain hemicellulose, cellulose, and lignin connected by b-1-4-linkages and hydrogen bonds [8,20]. This bond can be removed in the framework through the pyrolysis process of $\mathrm{N}_{2}-\mathrm{CO}_{2}$ to produce carbon nanofibers with different surface morphologies. During high-temperature pyrolysis, biomass that has a complex organic structure undergoes decomposition in stages. This begins with the evaporation of water vapor and volatile elements followed by the breakdown of complex compounds including hemicellulose, cellulose, and lignin [19]. Furthermore, the pyrolysis process of $\mathrm{N}_{2}-\mathrm{CO}_{2}$ separates and breaks the chemical bonds of functional groups from cellulose [13]. The resulting thermochemical reaction is released in the form of oxygen and carbon monoxide to produce pure carbon and nanofibers [42]. This nanofiber structure improves the performance of the supercapacitor electrode as energy storage due to its high surface area, tunable porosity, and high mechanical and structural stability. In addition, it has a diameter lower than $500 \mathrm{~nm}$ with high thermal and electrical conductivity as well as a good loading efficiency $[43,44]$.
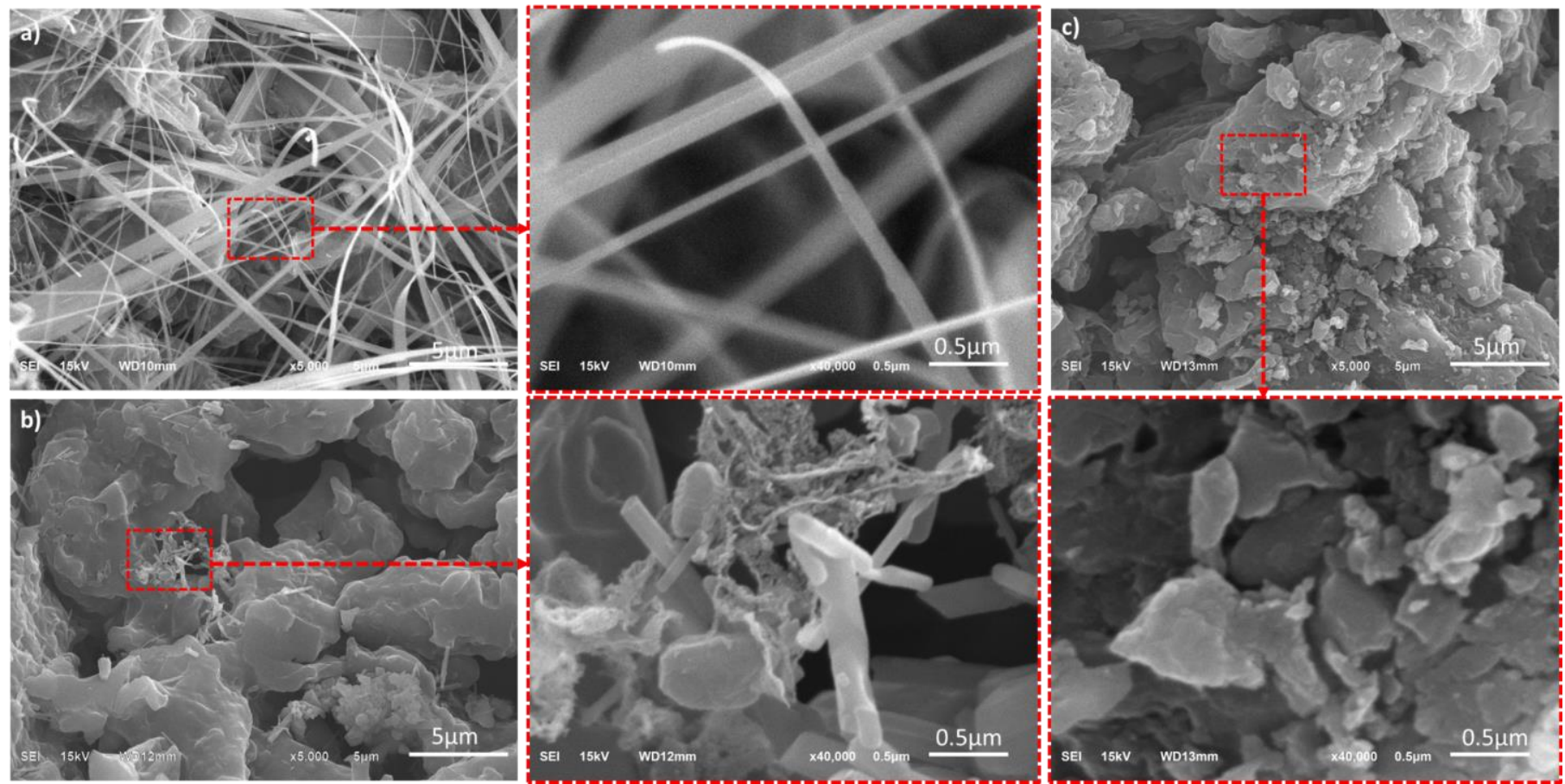

Fig. 3. SEM image for (a) TD-NaOH; (b) TD- $\mathrm{ZnCl}_{2}$; and (c) $\mathrm{TD}-\mathrm{H}_{3} \mathrm{PO}_{4}$

Figure $3 \mathrm{~b}$ also shows a slightly different morphological structure to the aggregation over the size range $299-723 \mathrm{~nm}$. In the enlarged area selection, there is a combination of nanofiber and pore interconnection for the TD- $\mathrm{ZnCl}_{2}$ sample, and the resulting fiber diameter ranges from $83-162 \mathrm{~nm}$ in size. $\mathrm{ZnCl}_{2}$ as a dehydrating agent directly erodes the constituent components of the sample including cellulose. Therefore, it reduces the density of the fibers, aggregations, and the formation of hierarchically connected pores, which were visible on the surface of the sample. The impregnation of $\mathrm{ZnCl}_{2}$ on carbon coin provided a sponge-like pore structure which allowed activated carbon to have a combination of various sizes including micropores, mesopores, and macropores [45]. These pores store more ionic charges at the electrode/electrolyte interface while providing a 3D ion diffusion pathway [46,47]. Furthermore, they can increase and maintain the energy and power density of the supercapacitor. These properties caused the $\mathrm{TD}-\mathrm{ZnCl}_{2}$ sample to have relatively higher electrochemical behavior compared to others as confirmed in the $\mathrm{CV}$ and GCD profiles discussed below.

Moreover, $\mathrm{H}_{3} \mathrm{PO}_{4}$ impregnation followed by hightemperature pyrolysis displayed the surface morphology covered by larger aggregations in the size range of $1.2-2.3 \mu \mathrm{m}$ as shown in figure $3 \mathrm{c}$. Also, $\mathrm{H}_{3} \mathrm{PO}_{4}$ as a strong acid reduced the nanofibers on the surface of the sample as confirmed by the enlarged selection area in the SEM micrograph. The visible pores showed a larger size range, and their expansion reduced the porosity and surface area of the carbon electrode as well as the capacitive properties of the sample.

\subsection{Element status of carbon coin nanofiber}

The elemental composition of the TD-NaOH, TD- $\mathrm{ZnCl}_{2}$ and $\mathrm{TD}-\mathrm{H}_{3} \mathrm{PO}_{4}$ samples was analyzed using energy dispersive spectroscopy (EDS). Table 2 summarizes the elements present in carbon coins nanofiber at different chemical activation of $\mathrm{NaOH}, \mathrm{ZnCl}_{2}$, and $\mathrm{H}_{3} \mathrm{PO}_{4}$. It has the highest percentage for all carbon monolith samples. A high percentage implies that most of the volatile and non-carbon content has been removed during the activation process [48]. The $\mathrm{ZnCl}_{2}$ impregnation indicates an increasing percentage of carbon. It showed that the decomposition of non-carbon compounds such as organic acids, volatile, and tar occurs effectively [49]. This analysis is confirmed by the reduction of the density of the coin described previously. At TD-NaOH, and TD- $\mathrm{H}_{3} \mathrm{PO}_{4}$ samples, the percentage of carbon is reduced slightly with the addition 
of more oxygen components. This is beneficial to provide wettability of the samples and exhibited the presence of pseudo-capacitance in the electrode material [50,51] as confirmed in the $\mathrm{CV}$ profile. Therefore, the $\mathrm{NaOH}$ and $\mathrm{H}_{3} \mathrm{PO}_{4}$ are more likely to form more oxygen bonds than carbon atoms. Furthermore, low levels of magnesium, calcium, phosphorus, and potassium come from the organic material [52] and the carbon element is almost similar to other biomass/waste-based studies as shown in table 3 .

Table 2. Element status of electrode carbon coins nanofiber tofu dregs-based

\begin{tabular}{lccc}
\hline \multicolumn{1}{c}{ Element } & TD-NaOH & TD- $\mathrm{ZnCl}_{2}$ & TD- $\mathrm{H}_{3} \mathrm{PO}_{4}$ \\
\hline Carbon & 85.39 & 87.88 & 84.21 \\
Oxygen & 12.70 & 9.09 & 9.08 \\
Magnesium & 0.48 & 0.61 & 2.60 \\
Calcium & 1.43 & 2.42 & 0.00 \\
Phosphor & 0.00 & 0.00 & 3.49 \\
Potassium & 0.00 & 0.00 & 0.62 \\
\hline
\end{tabular}

\subsection{Electrochemical analysis}

A The electrochemical performance of tofu dregs-based carbon coins nanofiber from TD-NaOH, TD-ZnCl 2 , and TD$\mathrm{H}_{3} \mathrm{PO}_{4}$ was evaluated through a two-electrode system in a $1 \mathrm{M}$ $\mathrm{H}_{2} \mathrm{SO}_{4}$ aqueous electrolyte. Figure 4 performs a typical $\mathrm{CV}$ profile for TD-NaOH, TD- $\mathrm{ZnCl}_{2}$, and TD- $\mathrm{H}_{3} \mathrm{PO}_{4}$ samples at a constant voltage of $0.0-1.0 \mathrm{~V}$ with a low scan rate of $1 \mathrm{mV} \mathrm{s}^{-1}$. Furthermore, the profile confirmed a distorted rectangular shape for all samples identifying the normal electrochemical properties of the double-layer capacitor (EDLC) due to the ionic charge which undergoes a rapid charge and discharge process [53]. Few samples showed a pair of redox peaks in the $0.3-0.6 \mathrm{~V}$ voltage range characterizing the presence of pseudocapacitive features due to the faradaic reaction [54,55]. This is because oxygen acts as self-doping in the electrochemical reaction of the sample, especially TD-NaOH and $\mathrm{TD}-\mathrm{ZnCl}_{2}$. However, these properties faded in the TD$\mathrm{H}_{3} \mathrm{PO}_{4}$ and TD-Inactivation samples. The largest closed area $\mathrm{CV}$ profile found in $\mathrm{TD}-\mathrm{ZnCl}_{2}$ confirmed the highest capacitive properties which were followed by TD-NaOH, TDH3PO4, and TD-Inactivation samples. Based on equation (2), the specific capacitance produced by the CV technique is 15 , 145, 148, $127 \mathrm{~F} \mathrm{~g}^{-1}$ for TD-Inactivation, TD-NaOH, TD$\mathrm{ZnCl}_{2}$, and $\mathrm{TD}-\mathrm{H}_{3} \mathrm{PO}_{4}$ samples, respectively. Furthermore, chemically activated samples were able to enhance the specific capacitance by almost 10 times, especially in the $\mathrm{ZnCl}_{2}$ activator agent which showed the highest specific capacitance of $148 \mathrm{~F} \mathrm{~g} \mathrm{~g}^{-1}$. The increase in the $\mathrm{TD}-\mathrm{ZnCl}_{2}$ samples was due to the combination of the morphological structure of the nanofiber and sponge-like pore. This allows the electrode to have high conductivity, high porosity, and diverse pore distribution to provide all-directional ion transport paths on the surface of the sample [45,56]. Based on the empirical formula of $\mathrm{SSA}_{\mathrm{xrd}}, \mathrm{TD}-\mathrm{ZnCl}_{2}$ is predicted to have a larger specific surface area. This allows the storage of more ionic charges at the electrode/electrolyte interface. In addition, $\mathrm{TD}-\mathrm{NaOH}$ has capacitive properties that are similar to $\mathrm{TD}-\mathrm{ZnCl}_{2}$ of $145 \mathrm{~F} \mathrm{~g}^{-1}$ even though it does not confirm the pore in the morphological structure.

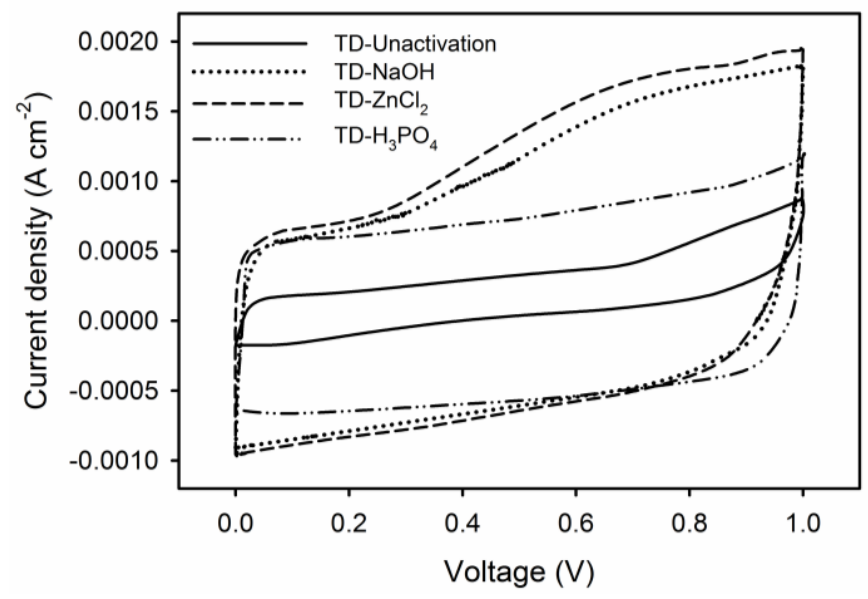

Fig. 4. CV profile of carbon coin nanofiber

This is because $\mathrm{NaOH}$ impregnation provides a nanofiber structure that dominates the surface of the sample. Therefore, it has high conductivity properties and maintains a relatively smooth ion transport pathway for electrolyte ion diffusion. However, $\mathrm{H}_{3} \mathrm{PO}_{4}$ impregnation has relatively lower capacitive properties than $\mathrm{ZnCl}_{2}$ and $\mathrm{NaOH}$ at $127 \mathrm{~F} \mathrm{~g} \mathrm{~g}^{-1}$ due to the reduction of the nanofiber on the sample surface. Through equations (3) and (4) the energy and power density of TDInactivation, $\mathrm{TD}-\mathrm{NaOH}, \mathrm{TD}-\mathrm{ZnCl}_{2}$, and $\mathrm{TD}-\mathrm{H}_{3} \mathrm{PO}_{4}$ were also evaluated with the values of $2.08,20.14,20.55$, and $17.07 \mathrm{Wh}$ $\mathrm{kg}^{-1}$, as well as the power density of $7.49,72.57,74.07$, and $63.56 \mathrm{~W} \mathrm{~kg}^{-1}$, respectively. Figure 5 shows the specific capacitance to the scan rate increasing from $1 \mathrm{mV} \mathrm{s}^{-1}$ to 10 $\mathrm{mV} \mathrm{s}^{-1}$. Furthermore, all samples showed reduced capacitive properties which were influenced by the expanding pore structure. However, the $\mathrm{TD}-\mathrm{ZnCl}_{2}$ maintained a specific capacitance of $54.42 \%$. Therefore, the $\mathrm{TD}-\mathrm{ZnCl}_{2}$ sample has better capacitive properties than TD-NaOH and $\mathrm{TD}-\mathrm{H}_{3} \mathrm{PO}_{4}$ which are only around $48 \%$ and $51 \%$.

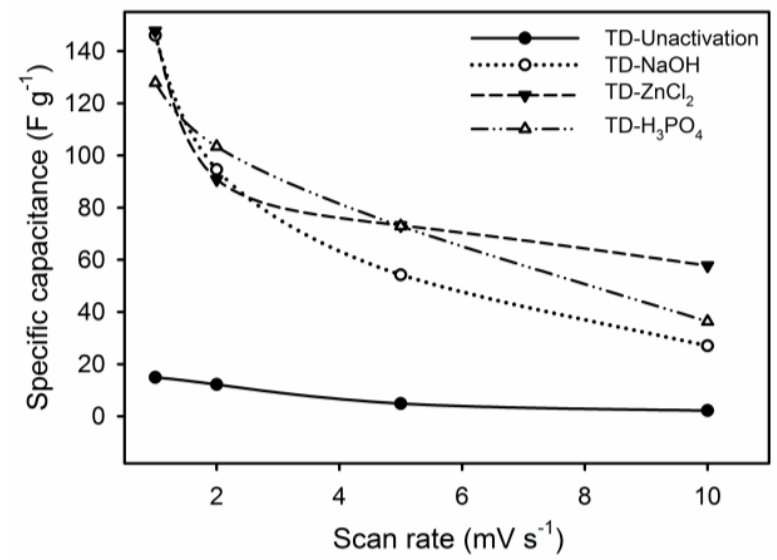

Fig. 5. Specific capacitance vs. scan rate of carbon coin nanofiber

To further validate the electrochemical properties of the activated carbon nanofiber, a two-electrode system was tested using the GCD technique at a constant current density of $1 \mathrm{~A}$ 
$\mathrm{g}^{-1}$. The GCD profiles for TD-Inactivation, TD-NaOH, TD$\mathrm{ZnCl}_{2}$, and $\mathrm{TD}-\mathrm{H}_{3} \mathrm{PO}_{4}$, samples showed a nearly symmetric triangular shape with a slight curvature. It characterizes normal electric double-layer capacitor properties followed by pseudocapacitance [57] as shown in figure 6. This is consistent with the $\mathrm{CV}$ analysis that has been discussed previously. Furthermore, activated carbon nanofiber impregnated with $\mathrm{ZnCl}_{2}$ showed the longest charge-discharge time indicating higher capacitive properties followed by TD$\mathrm{NaOH}$, TD-H3PO4, and TD-Inactivation. This trend data is relatively positive with the CV profile shown in figure 4 . Based on equation (3), the specific capacitances generated from $\mathrm{GCD}$ are $13,159,163$, and $134 \mathrm{~F} \mathrm{~g}^{-1}$ for TDInactivation, TD- $\mathrm{NaOH}, \mathrm{TD}-\mathrm{ZnCl}_{2}$, and $\mathrm{TD}-\mathrm{H}_{3} \mathrm{PO}_{4}$ samples respectively.

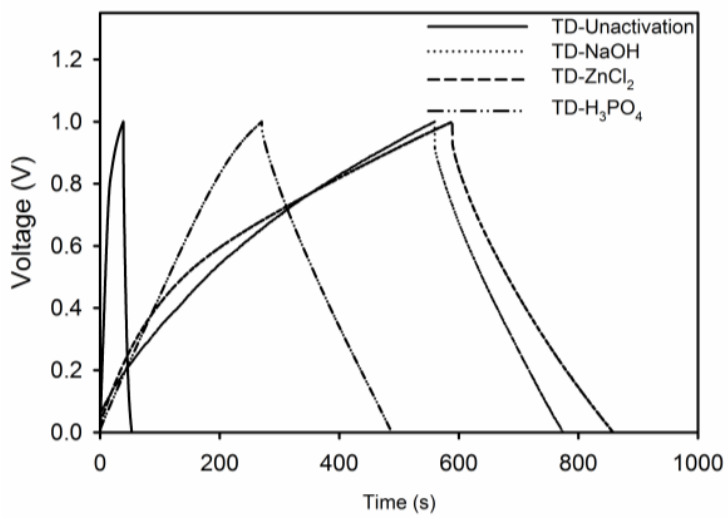

Fig. 6. GCD profile of carbon coin nanofiber

In addition, $\mathrm{ZnCl}_{2}$ impregnated coin carbon effectively showed the best capacitive properties compared to $\mathrm{NaOH}$, and $\mathrm{H}_{3} \mathrm{PO}_{4}$. This is because it provides high surface area, best amorphous properties, and high conductivity due to the combination of nanofiber and sponge-like pore structure. Based on the GCD profile, iR drop is also evaluated for all samples where the internal resistance of TD-Inactivation, TD$\mathrm{NaOH}, \mathrm{TD}-\mathrm{ZnCl}_{2}$, and $\mathrm{TD}-\mathrm{H}_{3} \mathrm{PO}_{4}$ is $76 \mathrm{~m} \Omega, 34 \mathrm{~m} \Omega, 21 \mathrm{~m} \Omega$, and $10 \mathrm{~m} \Omega$, respectively. However, TD- $\mathrm{H}_{3} \mathrm{PO}_{4}$ does not have the best capacitive properties because of its very low resistance. The pore expansion that occurs on the carbon surface provides an unobstructed ion transport path [58]. In addition, power and energy density are also evaluated using the GCD technique using equations (4) and (5). The energy densities for TD-Inactivation, TD-NaOH, TD- $\mathrm{ZnCl}_{2}$, and TD$\mathrm{H}_{3} \mathrm{PO}_{4}$ were $1.81,22.08,22.63,18.61 \mathrm{Wh} \mathrm{kg}^{-1}$ respectively. Meanwhile, the power densities were 6.52, 79.56, 81.54, and $67.06 \mathrm{~W} \mathrm{~kg}^{-1}$, respectively. These results are consistent with the analysis obtained from $\mathrm{CV}$ data. Furthermore, the capacitive properties obtained were compared with some of the materials for activated carbon electrodes as shown in table 3.

\section{Conclusion}

In summary, a simple approach has been proposed to obtain the waste-based porous carbon nanofiber without the addition of synthetic materials such as PTFE, PVP, or PVdF. Furthermore, activated carbon was prepared from tofu dregs with high nanofiber density. A combination of nanofiber and sponge-like pores morphology that allows for various pores including micro, meso, and macropores was featured by $\mathrm{ZnCl}_{2}$ impregnation. These allowed the sample to have more active sites for ionic charges to diffuse at the electrode/electrolyte interface. In addition, a seamless ion diffusion path covering all directions on the sample surface was provided. Carbon coins nanofiber contain oxygen content. It has wettability and hydrophilicity properties due to the presence of pseudocapacitance in the two-electrode system. Moreover, the electrochemical behavior results showed that the carbon coins nanofiber from tofu dregs exhibited excellent capacitive performance. This was particularly evident in the TD- $\mathrm{ZnCL}_{2}$ sample, which produced a high specific capacitance $163 \mathrm{~F} \mathrm{~g}^{-1}$ at a constant current density of $1 \mathrm{~A} \mathrm{~g}^{-1}$. The specific capacitance was still retained at approximately $54.42 \%$ in scan rate of $10 \mathrm{mV} \mathrm{s}^{-1}$. In addition, the excellent electrochemical capacitive behaviors were mainly attributed to the unique nanofiber and sponge-like pores structure. This study developed a facile approach to obtain porous carbon coins material with high performance for supercapacitor application.

Table 2. Electrochemical behavior from different sources for supercapacitor

\begin{tabular}{|c|c|c|c|c|c|c|c|c|c|}
\hline Sources & Method & $\begin{array}{l}\text { Carbon } \\
\text { type }\end{array}$ & $\begin{array}{c}\text { Adhesive } \\
\text { material }\end{array}$ & $\begin{array}{c}\text { Morphology } \\
\text { structure }\end{array}$ & Electrode type & $\begin{array}{c}\mathrm{C}_{\mathrm{sp}} \\
\left(\mathrm{F} \mathrm{g}^{-1}\right)\end{array}$ & $\begin{array}{c}\mathrm{E}_{\mathrm{sp}} \\
\left(\mathrm{Wh} \mathrm{kg}^{-1}\right)\end{array}$ & $\begin{array}{c}\mathrm{P}_{\mathrm{sp}} \\
\left(\mathrm{W} \mathrm{kg}^{-1}\right)\end{array}$ & Refs \\
\hline $\begin{array}{l}\text { Portunus } \\
\text { trituberculatus Crab }\end{array}$ & Bio-template & Powder & PTFE & Nanofiber & 2-Electrode & 128.5 & 4.46 & 50 & [59] \\
\hline MoS2/graphene & Electrospinning & Powder & PVDF & Nanosheet & 3-electrode & 211 & - & - & [60] \\
\hline $\mathrm{SnCl}_{4} \cdot 5 \mathrm{H}_{2} \mathrm{O} / \mathrm{PVA}$ & Electrospinning & Powder & PVDF & Nanofiber & 3-electrode & 105 & 5.1 & 242.2 & [61] \\
\hline Pinewood & Solar pyrolysis & Powder & PTFE & Nanofiber & 3-electrode & 349 & & & [22] \\
\hline Reeds & $\begin{array}{l}\text { Single } \\
\text { pyrolysis }\end{array}$ & Monolith & Free-binder & Nanofiber & 2-electrode & 141 & 4.89 & 35.32 & [62] \\
\hline $\mathrm{PF}+\mathrm{PVA}$ & Electrospinning & Powder & PVDF & Nanofiber & 3-electrode & 256 & - & - & [63] \\
\hline Cotonier strobili & $\mathrm{KOH}$ activation & Powder & PTFE & Strobili-fiber & 3-electrode & 346 & 33.04 & 160 & [15] \\
\hline Frozen tofu & $\begin{array}{l}\text { one-step } \\
\text { carbonization- } \\
\text { activation }\end{array}$ & Powder & PVDF & $\begin{array}{l}\text { Hierarchical } \\
\text { porous }\end{array}$ & 3 -electrode & 170 & 72 & 889 & [23] \\
\hline Tofu dregs & $\begin{array}{l}\text { Chemical } \\
\text { impregnation }\end{array}$ & Coin & Free-binder & Nanofiber & 2-electrode & 163 & 22.63 & 81.54 & $\begin{array}{l}\text { This } \\
\text { study }\end{array}$ \\
\hline
\end{tabular}




\section{Acknowledgements}

The research was financially supported by DRPM Kemenristek/BRIN, Republic of Indonesia through first year Project of PDUPT, contract No. 457/UN.19.5.1.3/PT.01.03/2021 with the title "Synthesis of Nano Carbon Biomass Waste-based as Raw Material of Supercapacitor Electrodes with High Energy and Power Densities".

\section{References}

1. W. Qu, Y. Xu, A. Lu, X. Zhang and W. Li, Converting biowaste corncob residue into high value added porous carbon for supercapacitor electrodes, Bioresour. Technol. 189 (2015) 285-291.

2. Poonam, K. Sharma, A. Arora and S.K. Tripathi, Review of supercapacitors: Materials and devices, J. Energy Storage. 21 (2019) 801-825

3. A. González, E. Goikolea, J.A. Barrena and R. Mysyk, Review on supercapacitors: Technologies and materials, Renew. Sustain. Energy Rev. 58 (2016) 1189-1206.

4. Z.S. Iro, C. Subramani and S.S. Dash, A brief review on electrode materials for supercapacitor, Int. J. Electrochem. Sci. 11 (2016) 1062810643

5. L. Zhang, et al., Three-dimensional structures of graphene/polyaniline hybrid films constructed by steamed water for high-performance supercapacitors, J. Power Sources. 342 (2017) 1-8.

6. E.E. Miller, Y. Hua and F.H. Tezel, Materials for energy storage: Review of electrode materials and methods of increasing capacitance for supercapacitors, J. Energy Storage. 20 (2018) 30-40.

7. T. Wang, et al., Flexible carbon nano fibers for high-performance freestanding supercapacitor electrodes derived from Powder River Basin coal, Fuel. 278 (2020) 117985.

8. S. Soltani, N. Khanian, T.S.Y. Choong and U. Rashid, Recent progress in the design and synthesis of nanofibers with diverse synthetic methodologies: Characterization and potential applications, New J. Chem. 44 (2020) 9581-9606.

9. K. Mensah-Darkwa, C. Zequine, P.K. Kahol and R.K. Gupta, Supercapacitor energy storage device using biowastes: A sustainable approach to green energy, Sustain. 11 (2019)

10. P. González-García, Activated carbon from lignocellulosics precursors: A review of the synthesis methods, characterization techniques and applications, Renew. Sustain. Energy Rev. 82 (2018) 1393-1414.

11. Y. Liu, J. Chen, B. Cui, P. Yin and C. Zhang, Design and Preparation of Biomass-Derived Carbon Materials for Supercapacitors: A Review, J. Carbon Res. 4 (2018) 53

12. M. Inagaki, H. Konno and O. Tanaike, Carbon materials for electrochemical capacitors, J. Power Sources. 195 (2010) 7880-7903.

13. T.R. Kumar, R.A. Senthil, Z. Pan, J. Pan and Y. Sun, A tubular-like porous carbon derived from waste American poplar fruit as advanced electrode material for high-performance supercapacitor, J. Energy Storage. 32 (2020) 101903.

14. E. Taer, Apriwandi, B.K.L. Dalimunthe and R. Taslim, A rod-like mesoporous carbon derived from agro-industrial cassava petiole waste for supercapacitor application, J. Chem. Technol. Biotechnol. 96 (2021).

15. X. Su, S. Li, S. Jiang, Z. Peng, X. Guan and X. Zheng, Superior capacitive behavior of porous activated carbon tubes derived from biomass waste-cotonier strobili fibers, Adv. Powder Technol. 29 (2018) 2097-2107.

16. Y. Liang, Y. Lu, G. Xiao, J. Zhang, H. Chi and Y. Dong, Hierarchical porous nitrogen-doped carbon microspheres after thermal rearrangement as high performance electrode materials for supercapacitors, Appl. Surf. Sci. 529 (2020) 147141.

17. S. Palisoc, J.M. Dungo and M. Natividad, Low-cost supercapacitor based on multi-walled carbon nanotubes and activated carbon derived from Moringa Oleifera fruit shells, Heliyon. 6 (2020) e03202.

18. E. Taer, A. Apriwandi, R. Taslim, A. Agutino and D.A. Yusra, Conversion Syzygium oleana leaves biomass waste to porous activated carbon nanosheet for boosting supercapacitor performances, J. Mater. Res. Technol. 9 (2020) 13332-13340.

19. J. Jose, V. Thomas, V. Vinod, R. Abraham and S. Abraham, Nanocellulose based functional materials for supercapacitor applications, J. Sci. Adv. Mater. Devices. 4 (2019) 333-340.

20. E. Azwar, et al., Transformation of biomass into carbon nanofiber for supercapacitor application-A review, Int. J. Hydrogen Energy. 43 (2018) 20811-20821.

21. E. Taer, K. Natalia, A. Apriwandi, R. Taslim, A. Agustino and R. Farma, The synthesis of activated carbon nano fiber electrode made from acacia leaves (Acacia mangium wild) as supercapacitors, Adv. Nat. Sci. Nanosci. Nanotechnol. 11 (2020) 25007

22. T. Wang, et al., Carbon Nanofibers Prepared from Solar Pyrolysis of Pinewood as Binder-free Electrodes for Flexible Supercapacitors, Cell Reports Phys. Sci. 1 (2020) 100079.

23. X. Sun,et al., Hierarchical porous carbon obtained from frozen tofu for efficient energy storage, New J. Chem. 42 (2018) 12421-12428.

24. H. Wang, C. Wang, Y. Xiong, C. Jin and Q. Sun, Simple Synthesis of NDoped Interconnected Porous Carbon from Chinese Tofu for HighPerformance Supercapacitor and Lithium-Ion Battery Applications, J. Electrochem. Soc. 164 (2017) A3832-A3839.

25. E. Taer, L. Pratiwi, Apriwandi, W.S. Mustika, R. Taslim and Agustino, Three-dimensional pore structure of activated carbon monolithic derived from hierarchically bamboo stem for supercapacitor application, Commun. Sci. Technol. 5 (2020) 22-30.

26. K. Surya and M.S. Michael, Novel interconnected hierarchical porous carbon electrodes derived from bio-waste of corn husk for supercapacitor applications, J. Electroanal. Chem. 878 (2020) 114674.

27. X. Ma, et al., Bamboolike Carbon Microfibers Derived from Typha Orientalis Fibers for Supercapacitors and Capacitive Deionization, J. Electrochem. Soc. 166 (2019) A236-A244.

28. A.B. Fuertes and M. Sevilla, Hierarchical microporous/mesoporous carbon nanosheets for high-performance supercapacitors, ACS Appl. Mater. Interfaces. 7 (2015) 4344-4353.

29. J. Deng, T. Xiong, H. Wang, A. Zheng and Y. Wang, Effects of cellulose, hemicellulose, and lignin on the structure and morphology of porous carbons, ACS Sustain. Chem. Eng. 4 (2016) 3750-3756.

30. M.Y. De Luna, et al., A thermogravimetric analysis of biomass wastes from the northeast region of Brazil as fuels for energy recovery, Energy Sources, Part A Recover. Util. Environ. Eff. 41 (2018) 1557-1575.

31. M.A. Martín-González, P. Susial, J. Pérez-Peña and J.M. DoñaRodríguez, Preparation of activated carbons from banana leaves by chemical activation with phosphoric acid: adsorption of methylene blue, Rev. Mex. Ing. Quim. 12 (2013) 595-608.

32. C. Kim, et al., Self-sustained thin Webs consisting of porous carbon nanofibers for supercapacitors via the electrospinning of polyacrylonitrile solutions containing zinc chloride, Adv. Mater. 19 (2007) 2341-2346.

33. B. Men, et al., High-performance nitrogen-doped hierarchical porous 
carbon derived from cauliflower for advanced supercapacitors, J Mater. Sci. 54 (2019) 2446-2457.

34. V. Yang, et al., Highly ordered hierarchical porous carbon derived from biomass waste mangosteen peel as superior cathode material for high performance supercapacitor, J. Electroanal. Chem. (2019) 113616.

35. Y. Li, X. Wang and M. Cao, Three-dimensional porous carbon frameworks derived from mangosteen peel waste as promising materials for CO2 capture and supercapacitors, J. CO2 Util. 27 (2018) 204-216.

36. O. Boujibar, A. Ghosh, O. Achak, T. Chafik and F. Ghamouss, A high energy storage supercapacitor based on nanoporous activated carbon electrode made from Argan shells with excellent ion transport in aqueous and non-aqueous electrolytes, J. Energy Storage. 26 (2019) 100958.

37. R. Taslim, T.R. Dewi, E. Taer, A. Apriwandi, A. Agustino and R.N. Setiadi, Effect of physical activation time on the preparation of carbon electrodes from pineapple crown waste for supercapacitor application, J. Phys. Conf. Ser. 1120 (2018) 012084.

38. R. Farma, et al., Preparation of highly porous binderless activated carbon electrodes from fibres of oil palm empty fruit bunches for application in supercapacitors, Bioresour. Technol. 132 (2013) 254 261.

39. B.S. Girgis, Y.M. Temerk, M.M. Gadelrab and I.D. Abdullah, X-ray Diffraction Patterns of Activated Carbons Prepared under Various Conditions, Carbon Sci. 8 (2007) 95-100.

40. M. Deraman, et al., A New Empirical Equation for Estimating Specific Surface Area of Supercapacitor Carbon Electrode from X-Ray Diffraction, Adv. Mater. Res. 1108 (2015) 1-7.

41. K. Kumar, R.K. Saxena, R. Kothari, D.K. Suri, N.K. Kaushik and J.N. Bohra, Correlation between adsorption and $x$-ray diffraction studies on viscose rayon based activated carbon cloth, Carbon N. Y. 35 (1997) 1842-1844.

42. Z. Dai, P. Ren, W. He, X. Hou, F. Ren and Q. Zhang, Boosting the electrochemical performance of nitrogen-oxygen co-doped carbon nano fibers based supercapacitors through esteri fication of lignin precursor, Renew. Energy. 162 (2020) 613-623.

43. L. Deng, et al., The enhancement of electrochemical capacitance of biomass-carbon by pyrolysis of extracted nanofibers, Electrochim. Acta. 228 (2017) 398-406.

44. X. Liu, et al., Flexible all-fiber electrospun supercapacitor, J. Power Sources. 384 (2018) 264-269.

45. Y. Liu, et al., Nitrogen/sulfur dual-doped sponge-like porous carbon materials derived from pomelo peel synthesized at comparatively low temperatures for superior-performance supercapacitors, J. Electroanal. Chem. 847 (2019) 113111.

46. A.R. Selvaraj, A. Muthusamy, Inho-Cho, H.J. Kim, K. Senthil and K. Prabakar, Ultrahigh surface area biomass derived $3 D$ hierarchical porous carbon nanosheet electrodes for high energy density supercapacitors, Carbon. 174 (2021) 463-474.

47. S. Yang, S. Wang, X. Liu and L. Li, Biomass derived interconnected hierarchical micro-meso-macro- porous carbon with ultrahigh capacitance for supercapacitors, Carbon. 147 (2019) 540-549.

48. M.M. Nasssar and G.D.M. Mackay, Mechanism of thermal decomposition of lignin, Wood Fiber Sci. 3 (1984) 441-453.

49. H. Wei, et al., Advanced porous hierarchical activated carbon derived from agricultural wastes toward high performance supercapacitors, J. Alloys Compd. 820 (2020) 153111

50. L. Wan, et al., Facile synthesis of nitrogen self-doped hierarchical porous carbon derived from pine pollen via $\mathrm{MgCO} 3$ activation for highperformance supercapacitors, J. Power Sources. 438 (2019) 227013.

51. X.Q. Lin, N. Yang, L. Qiu-Feng and R. Liu, Self-Nitrogen-Doped Porous Biocarbon from Watermelon Rind: A High-Performance Supercapacitor Electrode and Its Improved Electrochemical Performance Using Redox Additive Electrolyte, Energy Technol. 7 (2019).

52. C.I. Contescu, S.P. Adhikari, N.C. Gallego and N.D. Evans, Activated carbons derived from high-temperature pyrolysis of lignocellulosic Biomass, J. Carbon Res. 4 (2018) 9-13.

53. F. Razmjooei, K. Singh, T.H. Kang, N. Chaudhari, J. Yuan and J.S. Yu, Urine to highly porous heteroatom-doped carbons for supercapacitor: A value added journey for human waste, Sci. Rep. 7 (2017) 1-14.

54. H. Yang, J. Zhou, M. Wang, S. Wu, W. Yang and H. Wang, From basil seed to flexible supercapacitors: Green synthesis of heteroatomenriched porous carbon by self-gelation strategy, Int. J. Energy Res. 44 (2020) 4449-4463.

55. G.A. Yakaboylu, T. Yumak, C. Jiang, J.W. Zondlo, J. Wang and E.M. Sabolsky, Preparation of Highly Porous Carbon through Slow Oxidative Torrefaction, Pyrolysis, and Chemical Activation of Lignocellulosic Biomass for High-Performance Supercapacitors, Energy and Fuels. 33 (2019) 9309-9329.

56. K. Sun, et al., Oxygen-containing hierarchically porous carbon materials derived from wild jujube pit for high-performance supercapacitor, Electrochim. Acta. 231 (2017) 417-428.

57. J. Zhang, et al., N-doped hierarchically porous carbon derived from grape marcs for high-performance supercapacitors, J. Alloys Compd. 854 (2021) 157207.

58. Y. Zhang, et al., Review of macroporous materials as electrochemical supercapacitor electrodes, J. Mater. Sci. 52 (2017) 11201-11228.

59. Z. Shang, et al., Chitin nanofibers as versatile bio-templates of zeolitic imidazolate frameworks for $\mathrm{N}$-doped hierarchically porous carbon electrodes for supercapacitor, Carbohydr. Polym. 251 (2021) 117107.

60. H. Fu, et al., Single layers of MoS2/Graphene nanosheets embedded in activated carbon nanofibers for high-performance supercapacitor, J. Alloys Compd. 829 (2020) 154557.

61. Z. Liu,et al., Mesoporous carbon nanofibers with large cage-like pores activated by tin dioxide and their use in supercapacitor and catalyst support, Carbon. 70 (2014) 295-307.

62. R. Taslim, et al., Synthesis of High Porous Activated Carbon Nanofibers using the Single-Step Pyrolysis of Reeds Waste and Its Applications in Supercapacitor Electrodes, Technol. Reports Kansai Univ. 62 (2020) 5629-5641.

63. C. Ma, et al., Preparation and one-step activation of microporous carbon nanofibers for use as supercapacitor electrodes, Carbon N. Y. 51 (2013) 290-300. 